\title{
Original Article \\ Evaluation of Short Term Fever with Flu like Symptoms in a Tertiary Level Hospital in Bangladesh
}

\author{
Majumder MMI ${ }^{1}$, Ahmed $\mathrm{MT}^{2}$, Nath $\mathrm{SCD}^{3}$
}

\begin{abstract}
Short term fever, a major public health concern is commonly caused by influenza virus. This is a crosssectional surveillance study designed to identify common causes of short term fever and diversity of causative different viral strains specially influenza virus, done in medicine and pediatrics department, Comilla Medical College Hospital, Bangladesh from November 2013 to October 2014. Patients having fever with flu like symptoms for less than 7 days was selected. Nasopharyngeal swab was analyzed by RT-PCR for detection of influenza $A$ and $B$ with other respiratory virus. Routine blood test, Malaria detection, blood culture for Salmonella, urine culture was done.Out of 529 patients virus was isolated in 122, of which Influenza, non influenza and mixed viral pathogens was isolated in 65,48 and 9 patients respectively. Salmonella, Malarial parasites and urinary tract infection (UTI) was found in 40, 4 and 8 cases respectively. Sixty five patients was detected influenza $A$ and $B$ (31vs34), with both $A \& B$ in one patient. Most of Influenza $A$ and $B$ cases were found in early monsoon. Among Influenza $A$ positive cases, 29 belonged to $\mathrm{H} 3 \mathrm{~N} 2$ and 2 cases $\mathrm{H} 1 \mathrm{N1}$ (pdm09) subtype. This study revealed influenza $A$ and $B$, salmonellosis and other non influenza viruses as main etiology of short term fever. RT PCR for virus is an important investigation for viral detection. Blood and urine culture is adjunctive investigation to detect salmonellosis and UTI. No avian and swain flue was detected.
\end{abstract}

Keywards: Short term fever, flu like symptoms, influenza virus, RT-PCR, culture.

1. Corresponding Author:

Dr. Md. Mahabubul Islam Majumder

Professor and Head, Department of Medicine

Comilla Medical College, Bangladesh.

e-mail-mahabubmazumder@yahoo.com

2. Dr. Md. Tarek Ahmed

Associate Professor, Department of Medicine

Comilla Medical College, Bangladesh.

3. Dr. Sopan Chandra Deb Nath

Medical Officer (disease control)

Upazila Health Complex, Kabirhat, Noakhali, Bangladesh.

\section{Introduction}

Short term fever with flu like symptoms is a major public health concern globally which is commonly caused by viruses, out of which influenza virus most common. Other common causes are enteric fever, malaria and urinary tract infection (UTI). Influenza is caused by influenza viruses A and B. The emergence of different influenza viruses caused by antigenic shift results in influenza pandemic. ${ }^{1}$ Risk for complications and death following influenza infection is higher among young children, pregnant women, older persons, and persons with some chronic medical conditions ${ }^{2}$ According to the Centers for Disease Control and Prevention, 5 to 20 percent of the population is infected with the flu each year in the United States $^{2}$. The World Health Organization (WHO) reports that throughout the world, annual outbreaks result in 3-5 million severe cases and results 250,000 to 500,000 deaths $^{2}$. Influenza A viruses are divided into subtypes based on two proteins on the surface of the virus: the hemagglutinin $(\mathrm{H})$ which has 18 different sub type and the neuraminidase $(\mathrm{N})$ has got 11 different neuraminidase subtypes. ${ }^{1,3}$ In the spring of 2009, a new influenza A (H1N1) virus emerged to cause illness in people. ${ }^{1}$ That virus (often called "2009 H1N1") has now replaced the H1N1 virus that was previously circulating in humans. ${ }^{1}$ Occasionally, viruses are transmitted from wild aquatic birds to domestic poultry which may cause an outbreak and give rise to human influenza pandemics. ${ }^{4,5}$ Three influenza pandemics occurred in the $20^{\text {th }}$ century each following a major genetic change in the virus and killed millions of people which is highly virulent and had a direct adaptation to human ${ }^{6}$. A new strain of highly pathogenic avian influenza A (H5N1) has been circulating among birds in eastern Asia since $1996^{7}$ The virus has gradually expanded the host range from wild to domestic birds and animals and is becoming more pathogenic. In Asia in the 1990s a deadly avian strain of H5N1 has posed the greatest influenza pandemic threat. Common cold is a less severe disease different from influenza may sometimes confusedwith influenza. ${ }^{8}$ Parainfluenza can cause short term fever in milder form. UTI, malaria, enteric fever are common cause of febrile illness in our country. Some of the patients of enteric fever sometimes present with flu like symptoms ${ }^{9}$ and simultaneously classical step ladder pattern of fever is altered by analgesic and antibiotics which make it difficult 
to differentiate from flu or other viral illness. Bangladesh is the eighth most populous country in the world ${ }^{10}$ with low environmental hygiene and poor health sector related economical support. So there is every chance of rapid spread of infection. To prevent such hazards, it is necessary to identify common possible causes of short term fever caused by common viruses including influenza virus bacteria and parasites. This surveillance study was designed to evaluate common etiology of short term fever with flu like symptoms and diversity of viral strains specially influenza virus.

\section{Materials and Methods}

This is a cross-sectional surveillance study done in Comilla Medical College Hospital, Comilla for 1 year during the period of $1^{\text {st }}$ November 2013 to $30^{\text {th }}$ October 2014. All indoor and outdoor patients of medicine and pediatrics department presented with history of fever, cough, sore throat and running nose for less than 7 days was included in this study. Detailed history regarding age, socioeconomic status, residential status, seasonal effect, sanitation, travelling history, family history was collected in prescribed data collection form. To determine common viral causes like influenza, with proper aseptic measures, swab was collected from throat \&nasopharynx and kept in viral transport media. Specimens was directly stored at dry shippers at or below -700c and transported to icddr,b Dhaka virology laboratory and stored in liquid nitrogen dewars at or below $-70^{\circ} \mathrm{c}$ until time of analysis. Sample was analyzed by real time reverse transcriptasepolymerase chain reaction (RT-PCR) for detection of influenza $\mathrm{A}$ and $\mathrm{B}$, as well as $\mathrm{H} 1, \mathrm{H} 3$, two different versions of $\mathrm{H} 5$, six other respiratory viruses (human metapneumovirus (hMPV), respiratory syncytal virus (RSV), parainfluenza virus $1,2 \& 3$ and adenovirus. A subset specimens of severe $\backslash$ respiratory tract infection was also be tested for more than 21 respiratory pathogens using Taqman Array Card. Negative for the above respiratory pathogens was also tested for new pathogen discovery This project is being continued in joined collaboration with icddr,b Dhaka. Blood was examined for complete count and malarial parasites. Urine for $\mathrm{R} / \mathrm{M} / \mathrm{E}$ with culture and sensitivity was done by Kirby- Bauer disc diffusion technique using Muller Hinton Agar as per recommendation of clinical and Laboratory Standard Institute $^{11}$. After aseptic precaution $10 \mathrm{ml}$ blood from adult and $7 \mathrm{ml}$ blood from pediatric patient was collected and was transfer to bottle containing $50 \mathrm{ml}$ and $30 \mathrm{ml}$ media of automated blood culture system for adult and pediatric patient respectively. It was incubated up to 5 days for salmonella. Growth was isolated and anti microbial susceptibility were tested by Kirby- Bauer disc diffusion technique using Muller Hinton Agar as per recommendation of clinical and Laboratory Standard Institute $^{12}$.

\section{Results}

Our analysis included indoor and outdoor patients that participated in this study during the period of $1^{\text {st }}$ November' 2012 to $31^{\text {st }}$ October' 2013. Descriptive statistics were used to summarize and processing of all results from prescribed data collection form and laboratory results. This study was in collaboration of icddr,b, Dhaka, Bangladesh, for their virological report based on RT-PCR and also investigations from Comillamedical college hospital microbiological laboratory. Baseline characteristics shown in table I. It can be noted that most of the patients were from middle class family (73\%) and rural area (68\%). Out of 529 patients $298(56.32 \%)$ was male.

\begin{tabular}{|c|c|c|}
\hline Age ranges (in years) & Frequency & Percentage \\
\hline $1-15$ & 22 & 4.2 \\
\hline $16-24$ & 139 & 26.3 \\
\hline $25-39$ & 169 & 31.9 \\
\hline $40-59$ & 127 & 24 \\
\hline$\leq 60$ & 72 & 13.6 \\
\hline Total & 529 & 100.0 \\
\hline \multicolumn{3}{|l|}{ Sex distribution } \\
\hline Male & 298 & 56.32 \\
\hline Female & 231 & 43.66 \\
\hline \multicolumn{3}{|l|}{ Educational status } \\
\hline Illiterate & 224 & 42.3 \\
\hline Primary & 106 & 20.03 \\
\hline SSC & 96 & 18.2 \\
\hline $\mathrm{HSC}$ & 75 & 14.2 \\
\hline Graduate & 28 & 5.29 \\
\hline \multicolumn{3}{|l|}{ Socio-economic status } \\
\hline Lower class & 114 & 27.2 \\
\hline Middle class & 357 & 67.5. \\
\hline Higher class & 28 & 5.2 \\
\hline \multicolumn{3}{|l|}{ Residential status } \\
\hline Rural & 360 & 68.04 \\
\hline Urban & 169 & 31.95 \\
\hline \multicolumn{3}{|l|}{ Associated disease } \\
\hline Diabetes mellitus & 9 & 1.7 \\
\hline Hypertension & 2 & 0.37 \\
\hline Coronary heart disease & 14 & 2.64 \\
\hline COPD & 04 & 0.74 \\
\hline Asthma & 48 & 9.07 \\
\hline \multicolumn{3}{|l|}{ Personal history } \\
\hline Tobacco chewing & 19 & 3.6 \\
\hline Smoker & 24 & 4.53 \\
\hline Taking $\mathrm{OCP}$ & 9 & 1.7 \\
\hline
\end{tabular}

Table II shows viral infection was the most common cause of in short term pyrexia which consists of total $122(23 \%)$ cases. It can also observed that $67 \%$ cases no specific cause was identified.Out of total 529 patients 40 samples (7.56\%) shows blood culture positive for salmonella. The salmonella infection was not co infected with influenza and other respiratory viral infection. 
Table- II: Common pathogens identified in short term pyrexia $(n=529)$

\begin{tabular}{lcc}
\hline \multicolumn{1}{c}{ Aetiology } & Frequency & Percentage \\
\hline Viral pathogens & 122 & 23.06 \\
Salmonella & 40 & 7.56 \\
UT| & 8 & 1.52 \\
Malaria & 4 & .76 \\
\hline
\end{tabular}

In table III showed distribution of total viral pathogens. Out of total 122 viral pathogens $53.28 \%$ are single flu pathogen. Out of 65 influenza patients influenza A and B are $47 \%$ and $51.5 \%$ respectively and $1(1.51 \%$ ) patient had both influenza A\&B virus.

Table-III: Distribution of total viral pathogens $(n=122)$

\begin{tabular}{lcc}
\hline \multicolumn{1}{c}{ Pathogens } & Frequency & Percent \\
\hline Single flu & 65 & 53.28 \\
Single non-flu & 48 & 39.34 \\
Mixed & 9 & 07.38 \\
Total= & 122 & 100 \\
\hline
\end{tabular}

Table- IV: Distribution influenza A subtypes $(n=62)$

\begin{tabular}{lcc}
\hline \multicolumn{1}{c}{ Influenza A subtypes } & Frequency & Percent \\
\hline H3N2 & 29 & 93.55 \\
H1N1(10dm09) & 2 & 6.45 \\
Total & 31 & 100 \\
\hline
\end{tabular}

Influenza A sub typing shown in table $\mathrm{V}$ where most of the patients $(93.55 \%)$ are belongs to H3N2 subtype.

Table- V: Seasonal variation of influenza viruses: $(n=62)$

\begin{tabular}{l|cc|cccc}
\hline Months & Sample & flu & flu percent & A & B & A+B \\
\hline Nov-2013 & 38 & 4 & $11 \%$ & 3 & 1 & - \\
Dec-2013 & 34 & 2 & $6 \%$ & - & 2 & - \\
Jan-2014 & 61 & 3 & $5 \%$ & - & 3 & - \\
\hline Feb-2014 & 50 & 2 & $4 \%$ & - & 2 & - \\
\hline Mar-2014 & 60 & 3 & $5 \%$ & 1 & 2 & - \\
Apr-2014 & 47 & 3 & $6 \%$ & 1 & 2 & - \\
May-2014 & 43 & 1 & $2 \%$ & 1 & - & - \\
Jun-2014 & 43 & 18 & $42 \%$ & 16 & 1 & 1 \\
Jul-2014 & 34 & 17 & $50 \%$ & 8 & 9 & - \\
Aug-2014 & 35 & 8 & $23 \%$ & 1 & 7 & - \\
Sep-2014 & 42 & 2 & $5 \%$ & - & 2 & - \\
Oct-2014 & 42 & 3 & $7 \%$ & - & 3 & - \\
\hline
\end{tabular}

Table VI shows seasonal variation of influenza A viruses. Most of the samples were collected in between January to March and maximum flu +ve sample (35 samples) was found in June and July in the early Monsoon.

Table- VI: Respiratory virus other than influenza: $(n=57)$

\begin{tabular}{lcc}
\multicolumn{1}{c}{ Organisms } & Frequency & Percent (out of total virus ) \\
\hline Parainfluenza virus 1 & 4 & 3.27 \\
Parainfluenza virus 2 & 2 & 1.64 \\
Parainfluenza virus 3 & 6 & 4.92 \\
Human metanneumovirus & 5 & 4.1 \\
Respiratory syncytial virus & 19 & 15.57 \\
Adenovirus & 12 & 9.84 \\
Mixed & 9 & 7.38 \\
Total & 57 & 46.72 \\
\hline
\end{tabular}

\section{Discussion}

Considering demography, economic profile and social condition of our country, infectious disease are more common in Bangladesh, South East Asia including Bangladesh and male patients seek more medical attention than female. Viral infection endemic occurred in different parts of the world although no such epidemic was recorded in Bangladesh. Viral fever, enteric fever, urinary tract infection, malaria are the most common causes of febrile illness in our country. Short duration fever in developing countries is due to multifaceted infection by bacteria, virus and parasites ${ }^{13}$. For rational treatment, identification of causes is vital because of misuse and overuse of antibiotics causes antibiotic resistance which is a growing problem across the world. ${ }^{14}$ In this study, out of 529 collected specimens $66(12.47 \%)$ were influenza positive although all of these patients presented in our hospital with influenza like symptoms. Another study by ICDDRB during May 2007 and December 2008 the shows out of total 3,699 patients, $385(10 \%)$ were influenza positive which was similar to our study. ${ }^{15}$ RT-PCR shows no avian influenza and swain flu virus. We can also conclude that common influenza vaccine could be effective in $12 \%$ patients of short term fever with influenza like symptoms. In this study influenza peaked in JuneJuly, early Monson which is similar to a community-based survey in Thailand. ${ }^{16}$ Press release Hong Kong shows highest flu activity was recorded in late May. ${ }^{17}$ Viral aetiology was confirmed in $122(23 \%)$ patients where plan of treatment should be only supportive. Out of total 529 blood cultures S. typhi and S. paratyphi was found in $6.80 \%$ and $0.76 \%$ patients respectively. UTI was found in $1.57 \%$ patients. It can be concluded that antibiotics has definite role in $9.13 \%$ patients. Most of our patients of pyrexia of acute onset treated with antimicrobial agent where antibiotic has got no role in all patients. We recommend using antibiotics according to culture and sensitivity report. Widespread use of antimicrobial drugs in general population will lead to develop antimicrobial resistance. All in tertiary level hospital we should arrange all modern facilities for detection of viruses, bacteria and parasites. We acknowledge icddr,b Dhaka for performing RT PCR for identification of viruses. All the authors 
credit equally for the study and preparing the manuscript. Most of Influenza A and B cases were found in June and July, in early monsoon. Influenza A positive cases, belonged to H3N2 and cases H1N1 (pdm09) subtype. This study revealed influenza A and B, salmonellosis and other non influenza viruses as etiology of short term fever. RT PCR for virus is important investigation for viral detection. Blood for culture and sensitivity is adjunctive investigation to detect salmonellosis. No avian and swain flue was detected.This study revealed influenza A and B, other non influenza viruses and salmonellosis as etiology of short term fever. Most of Influenza A and B cases were found in early monsoon. Influenza A positive cases, belonged to H3N2 and H1N1 (pdm09) subtype. RT PCR for virus is important investigation for viral detection. No avian and swain flue was detected.

\section{References}

1. Centers for disease control and prevention. Influenza (Flu) virus, Seasonal Influenza (Flu). Aug 19, 2014. http//www.cdc.gov/ flu/about/virus.

2. Centers for disease control and prevention. Novel H1N1 Flue. Background on the situation. Flu Over view Incidence and Prevalence of Influenza. June 11, 2009.www.cdc./gov/h1n1flu/ background.

3. Hay A, Gregory V, Douglas A, Lin YP. Philos Trans R Soc Lond B Biol Sci. 2001 Dec 29;356(1416):1861-70.

4. Klenk HD. Avian influenza: molecular mechanisms of pathogenesis and host range. Animal viruses: molecular biology. Caister Academic Press, UK. ISBN 978-1-904455-22-6.

5. Kawaoka Y. Influenza Virology: Current Topics. J. Antimicrob. Chemother. (2006) 58 (4): 909. doi: $10.1093 / \mathrm{jac} / \mathrm{dkl} 322$.

6. TaubenbergerJ. Reid A, Lourens R, Ruixue W, Guozhong J, Fanning T. Characterization of the 1918 influenza virus polymerase genes. Nature. 2005;437:889893.

7. Food and Agricultural Organization of the United Nations (FAO). Guiding Principles for Highly Pathogenic Avian Influenza Surveillance and Diagnostic Networks in Asia. 2004- 2005.www.fao.org/3/a-i0808e .
8. Eccles R. Understanding the symptoms of the common cold and influenza. Lancet Infect Dis. 2005 Nov;5(11):718-25.

9. Typhoid fever symptoms - Myo Clinic. July 2015. http//www.mayoclinic.org/diseases-condinions/ typhoid fever/basics/symptoms/con- 20028553.

10. Dinh P, Long H, Tien N, Mai L, Tuan L, Tan H, et al. Risk Factors for Human infection with Avian influenza A H5N1, Vietnam. Emerging infectious Disease. 2004;12(12):1841-1847.

11. University of Nebraska Medical Center Division of Laboratory Science 2015. Urine Cultures- General Procedure: University of Nebraska Medical Center Division of Laboratory Science Clinical Laboratory Science Program CLS 418/CLS 419

12. Kim Tj, Weinstein MP. Clinical microbiology and infection.Update on blood cultures: how to obtain, process, report, and interpret June 2013;19(6):513-520 Doc 10.1111/1469-0691.12180

13. Thybo S. Screening of people with fever returning to Denmark from "the tropics" Ugeskr Laeger. 2005: 17;167(42):4002-6.PubMed. PMID: 16232401.

14. Brian Krans. CDC: Be Smart When Treating Kids' Colds with Antibiotics. November 18, 2013. www.cdc.gov/getsmart/community

15. Food and Agricultural Organization of the United Nations (FAO). Overview of the HPAI (H5N1) situation in world- December 2007.

16. Chakrarat P, Hathaikan C, Sopon I, Pilaipan P, Sukhum C, Prasert A, et al. Monitoring the influenza pandemic of 2009 in Thailand by a community-based survey Journal of Public Health and Epidemiology. April 2011;3(4):187-193. Available online at http://www.academicjournals.org/jphe ISSN 2141-2316 (C)2011 Academic Journals.

17. Seasonal Influenza. Centre for Health Protection. Department of Health. The Government of the health Hong Kong Special Administrative

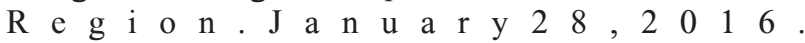
www.chp.gov.hk/en/view_content/14843.html. 